\title{
$O$ ativismo like: as redes sociais e a mobilização de causas
}

\author{
Sónia Pedro Sebastião \\ Doutora em Ciências Sociais (Universidade Técnica de Lisboa) \\ Professora na Universidade Técnica de Lisboa \\ ssebastiao@iscsp.utl.pt \\ Ana Catarina Elias \\ Mestranda em Comunicação Social (Universidade Técnica de Lisboa) \\ catarina30o8@hotmail.com
}

\begin{abstract}
Resumo Este artigo analisa a forma como a internet e as causas sociais se relacionam num contexto de participação política e cyberativismo. Para tal é feita uma análise das campanhas de causas sociais no Facebook e um inquérito on-line a utilizadores da internet e redes sociais, com a intenção de perceber a sua reação e o tipo de participação nestas campanhas.
\end{abstract}

Palavras-chave: internet, redes sociais, Facebook, causas sociais, campanhas.

\section{Introdução}

$\mathrm{C}$ OM a EVOLUÇão DA INTERNET, o modo de comunicar também evoluiu. O e-mail, o Voip e o Instant Messaging, entre outros, aproximam as pessoas de uma forma que antes não era possível. Por isso, é com alguma naturalidade que a internet se torna um espaço de partilha de opiniões, de desabafos, de definição de encontros, de trabalho, mas igualmente de movimentos de solidariedade. Se, no início, eram comuns as redes chain mail pedindo sangue, doação de medula, adopção de animais ou mesmo alertando para perigos e desaparecimentos, hoje em dia, esses movimentos de solidariedade chegam a novos instrumentos digitais, nomeadamente, às redes sociais.

Os websites de redes sociais, para além de revolucionarem a forma de comunicar, permitiram que outras acções se associassem, não servindo apenas para "fazer amigos" ou entrar em contacto com pessoas que não vemos há muito tempo. De fato, são cada vez mais uma via para a publicidade, para a promoção de produtos, para a promoção pessoal e para a consciencialização social e adesão a causas.

O Facebook ${ }^{1}$ é um claro exemplo, uma vez que actualmente tem um separador dedicado às causas sociais (Causes), sendo possível adicionar todas as causas e movimentos sociais que quisermos, com apenas um clique. Por outro lado, as marcas e as instituições estão a aproveitar esta rede social e os weblogues para se promoverem enquanto se associam a causas sociais. Em 2010, a cadeia de electrodomésticos e informática portuguesa Worten ${ }^{2}$ foi um dos exemplos. Por cada amigo que se associasse ao Facebook, a cadeia de lojas oferecia 0,25 euro à Ajuda de Ber-

1. Rede social criada por Mike Zuckerberg, disponível em: www.facebook.com

2. Loja portuguesa que vende produtos informáticos, electrodomésticos, entre outros, com várias lojas espalhadas pelo país, também disponível em: www.worten.pt 
ço. ${ }^{3}$ Múltiplas campanhas como estas nasceram e os utilizadores estão a aderir cada vez mais, o que prova a força das redes sociais, a facilidade da sua utilização e a vontade de participação dos indivíduos.

O presente artigo visa compreender a relação dos internautas, mais especificamente, dos utilizadores da rede social Facebook, com as causas sociais promovidas nesta rede. Através de um inquérito digital, serão investigadas as reacções dos utilizadores às correntes solidárias nas redes sociais, como estas se produzem e o porquê da sua criação. Por último, serão estudados alguns dos resultados de campanhas iniciadas neste tipo de websites.

O artigo está dividido em duas partes principais: na primeira, contextualizamos teoricamente a relação entre a internet e a participação social, assim como os tipos de cyberactivismo; na segunda parte, descrevemos o procedimento metodológico e analisamos os dados empíricos recolhidos.

\section{Internet e participação social}

A influência e o potencial das tecnologias da informação e da comunicação na participação política e social têm sido debatidos desde os anos 1970, devido ao uso de videoconferências, de câmaras de vídeo portáteis e da televisão por cabo, na produção mediática com o envolvimento de grupos da comunidade (Chadwick, 2006, p. 83).

Quando os estudos sobre a internet se debruçaram sobre a prática democrática, as perspectivas eram optimistas. Autores como Rheingold (1995), Toffler \& Toffler (1995) e Rash (1997) defendiam que a internet contribuiria para renovar o interesse dos cidadãos na democracia, graças ao seu empowerment ${ }^{4}$ e ao aumento da proximidade com os decisores políticos. O novo meio permitiria a criação de novos espaços de debate, pressão e influência no processo de comunicação política e de elaboração de políticas públicas. Tal seria possível devido às características dos meios digitais, tais como: o anonimato e a consequente redução dos constrangimentos sociais (Witschge, 2004, p. 113-117); a interactividade (comunicação muitos-para-muitos, base recíproca); a não existência de limites na rede global; a liberdade de expressão e a ausência de censura por parte das autoridades; a livre associação às "neotribos" (grupos com interesses semelhantes); e a produção de informação amadora que aumenta o número de produtores ("vozes") que desafiam os profissionais "tradicionais" e as entidades oficiais em termos de informação pública.

Contudo, o aumento de investigações sobre a relação entre a internet e a democracia veio evidenciar a necessidade de moderação do optimismo. Isto porque o nível de influência da internet no aumento do debate democrático e na aproximação dos cidadãos dos políticos é limitado (Hague \& Loader, 1999; Norris, 2001; Wilhelm, 2000; Howard \& Jones, 2004; Chadwick, 2006; Mirandilla, 2009; Ferber, Foltz, \& Pugliese, 2007; Carpini \& Keeter, 2002) e de alguma forma perigoso (Wilhelm, 2000).

Considerando investigações anteriores sumariadas por Park \& Perry (2008, p. 192-193), identificamos três perspectivas sobre a relação entre a internet e a participação dos indivíduos: (1) a optimista, de acordo com a qual a internet é um veículo de envolvimento cívico e de debate político; (2) a céptica, que reconhece o potencial da internet como meio de comunicação, mas sublinha que ela não tem de aumentar ou diminuir o envolvimento político, uma vez que este é socialmente determinado; e, finalmente, (3) a pessimista, que encara a internet como um meio de reforço das relações de poder e os padrões de participação existentes. Por si, a internet é dominada pelos jovens, influentes e poderosos, já por si motivados e envolvidos politicamente. Desta forma, são reforçadas as desigualdades de acesso político (Norris, 2001).

De acordo com Oates \& Gibson (2006, p. 1-2), a internet distingue-se dos outros meios dado que se trata de uma esfera virtual na qual todos os níveis do mundo político (actores políticos, órgãos de comunicação social e cidadãos) podem estar envolvidos em simultâneo. A internet quebra barreiras físicas, supera formas tradicionais de ligação e oferece novas formas de expressão cívica que são geridas electronicamente (Maria \& Rizzo, 2005, p. 76). Contudo, não é o medium que determina o seu uso: o medium pode servir para envolver todos os actores políticos, mas não garante a verificação desse envolvimento.

Katz (1997), Coleman (1999), Wilhelm (2000), Dahlgren (2001), Shane (2004), Chadwick (2006; 2009), Herrnson, Stokes-Brown \& Hindman (2007) e Mossberger, Tolbert \& McNeal (2008) são alguns dos autores que escreveram sobre a importância e os limites do uso das ferramentas da internet para aprofundar a relação entre os cidadãos e os actores políticos e as suas implicações na e-participação (participação política utilizando a internet). Como potencial forma de escapar da política top-down da democracia de massas, em que a política é dominada pelos

3. Instituição de caridade que abriga crianças carenciadas até os 3 anos de idade.

4. Entendido como a possibilidade de tomar decisões importantes no contexto cívico, e ser capaz de compreender as escolhas feitas e as suas implicações em termos políticos (Jenkins et al., 2009, p. 12-13). 
partidos políticos com baixo nível de participação e envolvimento dos cidadãos, a internet fornece meios para uma maior diferenciação de informação política e ideias, e (pelo menos) a possibilidade teórica de maiores níveis de envolvimento e participação nas negociações, com a possibilidade de feedback entre líderes e seguidores (McQuail, 2000, p. 135). Mas a falta de interesse dos seguidores e a crise de confiança nas instituições e nos actores políticos são limitações significativas ao envolvimento on-line, uma vez que não será por terem acesso às ferramentas digitais que os cidadãos se interessarão e se envolverão no debate político. O envolvimento e o compromisso dos cidadãos só serão possíveis se os actores políticos inspirarem confiança e preocupação com os cidadãos, e se os cidadãos perceberem que a sua opinião e sua participação são importantes e tidas em conta.

$\mathrm{Na}$ mesma medida e no nível da participação social, a internet trouxe grandes modificações para a sociedade, e as novas tecnologias, associadas às variadas utilizações empregues pelos indivíduos, são agora parte da sua vida quotidiana. A tecnologia avançada e os sistemas de informação têm vindo a transformar os sistemas de produção, distribuição, controlo e comunicação, levando a que a globalização seja um fenómeno dependente da comunicação mediada por computador (Langman \& Morris, 2003, p. 2). Consequentemente, estas tecnologias são cada vez mais utilizadas para a promoção de causas, a criação e a organização de movimentos sociais. Neste processo, a internet é uma das mais importantes e eficientes ferramentas tecnológicas, uma vez que é conveniente e económica, permitindo ao utilizador escolher o seu nível de actividade (Danitz \& Strobel, 2001, p. 162-164).

Como refere Passy (2002, p. 5), as identidades são criadas e moldadas através das relações sociais, nas quais as redes desempenham um papel fundamental. Neste processo, não podemos excluir as redes sociais baseadas na internet, cada vez mais um espaço de definição da identidade digital do internauta que passa pelo seu nível de participação.

A participação em movimentos sociais não é uniforme, por isso podemos identificar três tipos de perfis de participação: os activistas, com elevado envolvimento on-line e off-line; os contribuidores, que dão apoio, normalmente financeiro e de forma esporádica; e os subscritores, que estão no meio e cuja participação, podendo ser activa, é limitada ao ambiente on-line, ou seja, são activistas like.

Existem vários estudos sobre o envolvimento dos utilizadores em movimentos de solidariedade social, contudo eles visam à compreensão dos motivos que levam ao envolvimento dos indivíduos e não a aferir os níveis de envolvimento das participações dos indivíduos. Como exemplos encontramos Rosenthal et al. (1985) e Snow et al. (1980), que demonstram que as pessoas participam em movimentos sociais através de diversos canais e devido a inúmeros fatores (apud Passy \& Giugni, 1998, p. 2). Entre os motivos que levam à participação nos movimentos sociais têm sido apontadas: as recompensas pessoais, solidárias e sociais, bem como o enquadramento ideológico pessoal e a construção de capacidades várias (Langman \& Morris, 2003).

A maioria dos estudos realizados afirma, ainda, que são as perspectivas individuais que condicionam a vontade de participar nos movimentos sociais, nomeadamente: a percepção da efectividade da acção, o comportamento das autoridades políticas, os riscos da acção e a disponibilidade pessoal (Passy \& Giugni, 1998, p. 2). Embora estes quatro aspectos não tenham sido estudados em simultâneo, os autores são unânimes em apontar que os indivíduos participam em movimentos sociais quando consideram que o seu envolvimento fará a diferença. Nas palavras de Passy e Giugni, "the feeling that one's involvement would matter to the cause at hand is a strong incentive for actually becoming involved" (1998, p. 23).

No entanto, o nível de participação dos indivíduos acaba por não ser estudado, dado que o focus da investigação é normalmente o recrutamento e não a acção colectiva em si, na qual os diferentes tipos de participação permanecem "a black box in the study of social movements" (Passy \& Giugni, 1998, p. 2).

\section{Cyberactivism e slacktivism}

Como afirmam Langman e Morris, com a crescente utilização da internet e com a emergência do chamado internetworking e do cyberactivism, torna-se premente aumentar o campo de estudo dos movimentos sociais para que novas conclusões possam ser tiradas sobre a sua natureza social e implicações (2003, p. 14). A internet é uma nova forma de organização social e de activismo que partilha os objectivos articulados das antigas mobilizações democráticas, como o sufragismo ou até os direitos civis (Langman $\&$ Morris, 2003, p. 13).

Actualmente, as redes sociais são uma das formas mais utilizadas de participação em causas sociais. Segundo Kelly Richards, coautora do blogue O'Reilley Media, ${ }^{5}$ as redes sociais estão a contribuir largamente para o sucesso das causas sociais tendo, 
hoje em dia, um papel activo em aliciar os jovens para a sua participação. De fato, estas estão a acrescentar diversas aplicações que permitem este envolvimento, como Richards (2007) reafirma: "this generation can actually change the world while socializing in on-line communities”. O Facebook criou a aplicação "Causas"; o Friendster 6 permite que associações não lucrativas criem perfis, e o My Space ${ }^{7}$ lançou o canal "Impact", que apela à participação social e ao apoio a instituições.

No entanto, não são apenas as redes sociais que fomentam esta participação. Os weblogues e páginas pessoais são também veículos de participação e de apelo e, hoje em dia, são cada vez mais bem-sucedidos, uma vez que a internet permite uma distribuição alargada da informação no espaço e no tempo. Assim, os pedidos de apoio passam a ser internacionais, bem como as respostas e as participações neles. O que leva Denning a afirmar que: "social movements that are segmentary, polycentric, and networked have a very effective form of organization" (2001, p. 305).

A importância das redes sociais na internet tem merecido destaque em diversas conferências e workshops. Por exemplo, na Universidade de Harvard (abril de 2009) foi discutido o poder das redes sociais em convencer e propagar causas sociais e como estas podem se beneficiar desta nova moda.

Por isso, não é surpreendente que novas comunidades on-line de ajuda e apoio a causas estejam a ser criadas a todo o momento, o que prova a força das redes sociais e da internet. Como exemplo, na Estónia, mais de 50 mil pessoas foram mobilizadas através da internet para limpar o lixo da cidade e, no Egipto, foi criado um grupo do Facebook com mais de 70 mil pessoas que apoiavam a greve dos trabalhadores têxteis. A própria Pepsi fechou a sua fábrica em Burma devido aos constantes protestos dos activistas que inundaram a internet com as suas petições, weblogues e páginas contra a empresa: "a battle by global, electronically savvy activists was finally over. With computer modems, keyboards, electronic mail, web sites, long hours, and organization, they had forced the sodaand-snack-food giant to leave a land ruled by a regime that the activists considered illegitimate and repressive" (Danitz \& Strobel, 2001,p. 130).

O caso torna-se ainda mais interessante quando analisamos os países cujas ditaduras podem mesmo estar em risco devido à world wide web, sendo Burma um exemplo, pois a grande Pepsi cedeu à pressão e à má publicidade e deixou o país. No entanto, outra questão (e talvez a mais pertinente) impõe-se. Se hoje em dia a internet e os desenvolvimentos tecnológicos são fulcrais para um país, como pode um ditador (que necessita deles para uma contínua evolução do seu estado) controlar os seus cidadãos? Dado que, quanto mais um ditador permitir a utilização das novas tecnologias, maior o risco de perder o monopólio do controlo sobre a informação e sobre os canais de comunicação (Danitz \& Strobel, 2001, p. 137).

A resposta acaba por ser a forma como esta tecnologia é utilizada e entregue aos cidadãos. Temos o exemplo clássico da China, que tem diversos websites bloqueados como o Facebook, o Google, entre outros. No entanto, mesmo com esta limitação, muitas informações sobre os abusos praticados pelo regime são enviadas para fora do país: com recurso à internet. Esta, mesmo limitada, acaba por ser um veículo para as causas, dando poder aos chamados cybercampaigners, ${ }^{8}$ que, com a internet ao seu dispor, conseguem iniciar movimentos.

Um bom exemplo é o Egipto. Em 2010, milhares de jovens recorrem ao Facebook para convocar diversas manifestações que derrubaram um regime ditatorial com mais de trinta anos. O derrube do regime não foi provocado apenas pela utilização da internet. Contudo, a rede foi mobilizadora de protestos e foi a difusora de muitos vídeos amadores que mostravam o que muitas estações de televisão não conseguiam transmitir durante as primeiras manifestações. ${ }^{9}$ Coube à internet dar força ao protesto, sendo o meio que deu voz e imagem aos protestantes, uma vez que "one of the advantages of the Internet for activists and many other users, of course, is the fact that it allows them to dispense with the traditional 'filters' for news, including reporters and government officials" (Danitz \& Strobel, 2001, p. 165).

A situação tornou-se tão relevante que levou à criação de uma rede social apenas para as causas sociais. O seu nome é Jumo ${ }^{10}$ e pretende "ligar" projectos sem fins lucrativos aos seus apoiantes. O seu criador é cofundador do Facebook e teve a ideia após dirigir a campanha presidencial on-line de Obama.

Não obstante a sua capacidade mobilizadora, existem vários movimentos sociais que nascem e são alimentados nas redes sociais que permanecem no espectro virtual. Exemplos como o do Egipto, em que o movimento social é convocado para a rua e está na rua (off-line) são em menor número quando comparados com a criação de "páginas de causas" nas redes sociais que são partilhadas entre internau-

6. Rede social dedicada a jogos. Disponível em: www.friendster.com.

7. Rede social que passa actualmente por uma transformação, mas que teve sempre um grande papel na divulgação de novos artistas musicais, Disponível em: www.myspace.com.

8. Usuários que utilizam a internet como veículo para as suas campanhas.

9. No princípio da revolução, apenas os vídeos amadores difundidos na internet testemunhavam o que se passava no país.

10. Disponível em: http://www.jumo.com/. 
tas, cuja acção efectiva passa pelo pressionar da opção like ou pela colocação do nome numa petição electrónica (e-participação ou participação on-line). Este é o chamado slacktivism, ${ }^{11}$ termo anglófono pejorativo que denomina uma forma de participação social que se caracteriza como preguiçosa, pois está à distância de um clique, mas que provoca nos indivíduos uma sensação de participação social e de um impacto positivo importante na sociedade. No entanto, há que ter em conta que clicar num botão é bastante simples e não implica envolvimento nem preocupação; o que leva à "demissão" da maioria dos utilizadores que rapidamente esquecem o assunto. Ou seja, é uma participação sem continuação, sem implicações, sem emoção, sem empenhamento. Por muitas campanhas que um slacktivist "apoie", se não as acompanha, que preocupação ou envolvimento em causas revela?

E aqui encontramos o reverso da moeda. Se a internet, devido às suas características, permite lançar uma campanha social em nível nacional ou até mundial de forma gratuita, não estará igualmente a dessensibilizar os indivíduos para uma participação mais activa? Para Peter Simons, director do Institute for Ethical and Civic Engagement, da Universidade do Colorado, o slacktivism ou activismo like (como preferimos chamá-lo) é um activismo substituto, porque os indivíduos não têm trabalho, não saem de casa e não participam pessoalmente.

Contudo, Morozov enfatiza que, não existindo uma explicação para o porquê do envolvimento dos indivíduos em movimentos sociais, com a internet esta questão ainda se torna mais complexa: "there is no simple answer as to how and why people become involved in democratic social movements. The Internet makes the question especially complex. Does the net enable recruitment, or do people already disposed to activism manage to find activist groups via the net?" (2009).

Apesar do não envolvimento, os resultados do activismo like podem ser vantajosos e muitas empresas associam-se a estas causas para obter lucros. Assim, criam campanhas de ajuda que requerem a associação dos utilizadores ao Facebook da marca. O que leva as organizações e indivíduos (activistas ou não) a recorrer à web, sendo cada vez mais hábeis na sua utilização. A internet é actualmente um canal indispensável para estas organizações, uma vez que precisam de novas formas para apresentar as suas necessidades e projectos, fora do bastião do poder instituído (Langman \& Morris, 2003, p. 10).

Concluímos que a internet e as causas sociais estão intrinsecamente ligadas, uma vez que um alimenta o outro, estando as redes sociais na vanguarda do acontecimento, pois "whatever the ideological con- tent flowing through and shaping the Internet, cyberspace has made possible a plurality of new virtual 'public spheres' where a variety of otherwise marginal voices might be heard" (Langman \& Morris, 2003, p. 13).

\section{Nota metodológica}

Para Carlos Diogo Moreira, "o uso da informação disponível, qualquer que seja o seu carácter documental (numérico ou não numérico, elaborado ou em bruto) é praticamente indispensável em investigação social” (2007, p. 153).

De acordo com Moreira (2007), este método, à semelhança de outros, contém vantagens e desvantagens, sendo que as vantagens se justapõem às desvantagens. Para o presente trabalho, foram utilizados livros, artigos científicos, revistas da especialidade e ainda diversas notícias relacionadas com a internet, redes sociais e causas sociais, bem como notícias sobre resultados de campanhas iniciadas em redes sociais.

O inquérito por questionário, por sua vez, é um método pertencente à abordagem quantitativa, visto que os dados daqui obtidos serão alvo de uma análise quantitativa. Este método é, no entanto, falível, pois depende da autenticidade das respostas dadas, o que nem sempre acontece, uma vez que os inquiridos tendem a responder de forma politicamente correcta. Um questionário é por isso "um conjunto de perguntas estandardizadas de formulação idêntica, lidos literalmente e seguindo-se sempre a mesma ordem ao entrevistar-se cada inquirido" (Moreira, 2007, 233).

Para o presente trabalho, usamos perguntas abertas (para evitar direccionar as respostas) e fechadas (caracterização sociodemográfica e questão de resposta $\operatorname{sim} /$ não), sendo que o questionário foi utilizado com os seguintes objectivos:

1. saber se os utilizadores participam em causas sociais nas redes sociais;

2. investigar como participam delas;

3. identificar algumas das campanhas mais reconhecidas pelos utilizadores de redes sociais.

A amostra seleccionada é uma amostra bola de neve, uma vez que o questionário foi enviado por correio electrónico a vários contactos que depois o reenviaram, sendo também colocado no Facebook. A opção por este procedimento justifica-se com o objecto estudado. Como o trabalho é sobre redes sociais e como a intenção é investigar os utilizadores deste tipo de websites, pareceu-nos indicado colocar o link numa rede social para termos a garantia da utilização dela por parte dos respondentes. O questio- 
nário on-line foi realizado recorrendo ao programa Google Docs, encontrando-se no link https://spreadsheets.google.com/viewform?formkey $=\mathrm{dDhGekMz}$ OHZ4MzRZWHV3TWFId1MyOFE6MQ.

Foram obtidas 90 respostas, das quais 10 foram anuladas, uma vez que o questionário não estava completo, tendo a análise contemplado 80 respostas válidas.

Os nossos inquiridos são maioritariamente do sexo feminino (69\%), têm entre 18 e 34 anos (55 indivíduos); 10 têm entre 35 e 44 anos, 7 têm menos de 17 anos e 3 têm entre 45 e 54 anos (ver Gráfico 1).

Gráfico 1 - Idade dos inquiridos

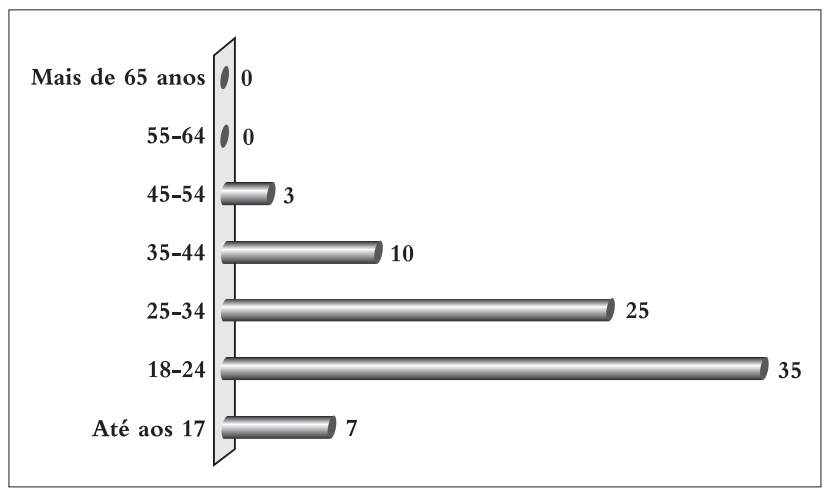

Em relação à sua ocupação principal, 35 inquiridos são estudantes, 7 estão desempregados e os restantes são empregados por conta de outrem (ver Gráfico 2).

Gráfico 2 - Ocupação principal dos inquiridos

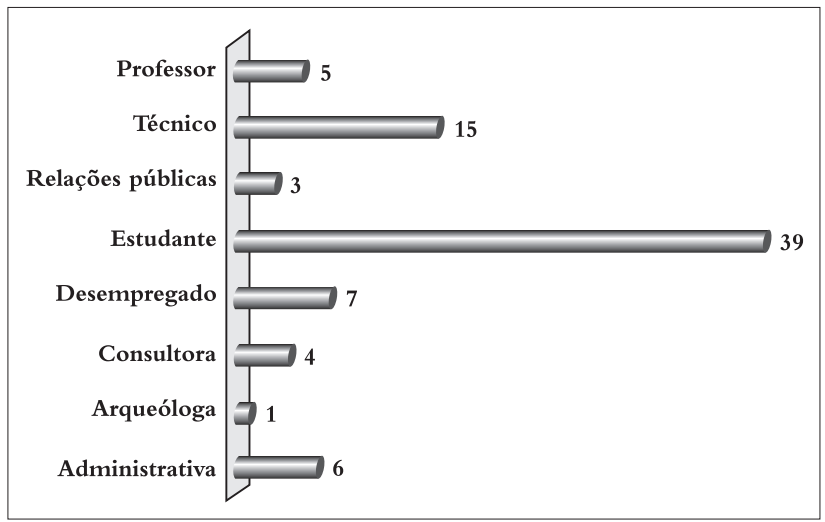

\section{Apresentação dos resultados}

Iniciamos o nosso questionário inquirindo os indivíduos sobre a sua presença nas redes sociais digitais (resposta múltipla). Apenas $8 \%$ não têm perfil em nenhuma rede social. A maioria dos inquiridos divide-se entre o Facebook (34\%) e o Hi5 (25\%). Os restantes inquiridos também estão presentes no Twitter $(20 \%)$, Linkedin (9\%) e 4\% noutras redes (Tuenti, Orkut, Wayne, Last.fm e My Space) (ver Gráfico 3).
Gráfico 3 - Redes sociais a que pertencem os inquiridos

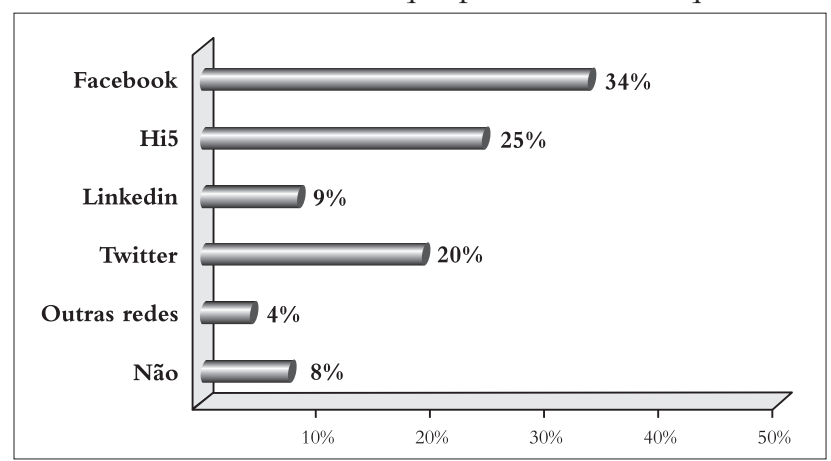

Quando questionados sobre a sua participação em causas sociais presentes nas redes sociais, 56\% dos inquiridos referem que não aderiram a nenhuma causa. Os que aderiram referiram ter participado: na Ajuda de Berço (Dê colo à ajuda de Berço); na utilização do separador Causes do Facebook; Arredonda; no apoio à União Zoófila e no apoio à Liga Portuguesa Contra o Cancro. Foram ainda referidos a campanha realizada pelo Fórum Almada de apoio à Ajuda de Berço e, ainda sem serem especificados, adesões a causas ambientais, contra a pobreza, aumento de tarifários e o novo acordo ortográfico.

Quando questionados sobre o porquê da sua adesão a causas sociais, os inquiridos justificaram-se com afirmações como: porque é fácil e rápido; porque é gratuito; porque fui convidado pelos meus amigos do Facebook; porque muitos fazemos a diferença. Comum a todas as justificações é o fato de os inquiridos afirmarem que contribuem porque sentem que podem fazer a diferença e o custo é extremamente reduzido: "apenas um clique".

Quanto aos inquiridos que referiram não aderir a causas nas redes sociais, justificaram a sua opção com as seguintes respostas: não usam as redes sociais com frequência; não acreditam na eficácia dessas acções e, por último, não consideram que participar nestas acções seja realmente ajudar. Nesta última categoria, encontramos diversos inquiridos (25\%) que afirmam que, para ajudar, não basta pertencer a um grupo numa rede social ou adicionar como amigo uma causa. É preciso participar activamente através da presença física, pessoal e cara a cara.

Em relação à forma de participação dos inquiridos nas causas sociais, a maioria referiu ter participado através da adesão a uma página do Facebook (49\%) seguindo-se a opção "cliquei em like", uma aplicação do Facebook, com 41\%. Os valores restantes dividemse em $6 \%$ para a assinatura de uma petição on-line e 4\% para "doei materiais e contribuí monetariamente para a associação" (ver Gráfico 4).

Quando questionados sobre a sua opinião sobre as redes sociais como veículo de divulgação e apoio às causas sociais, cerca de $83 \%$ dos inquiridos considera que as redes sociais são um bom local para a difusão 
das causas sociais, uma vez que têm uma grande audiência e participação e chamam a atenção para diversos assuntos. Quanto aos inquiridos que responderam negativamente, as suas justificações prendem-se ao fato de estas campanhas serem apenas na internet, o que, em termos materiais e de apoio físico, não se manifesta a favor das associações.

Gráfico 4 - Forma de participação dos inquiridos

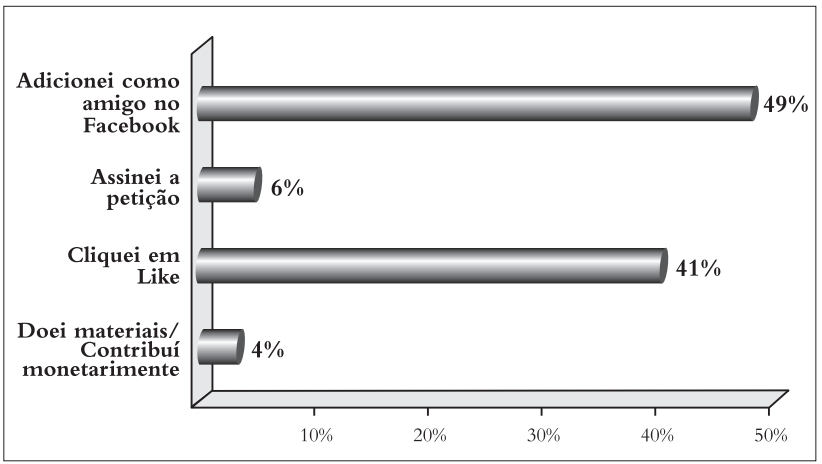

Quanto às campanhas, as mais recordadas (de forma espontânea) pelos inquiridos foram a campanha da Worten/Ajuda de Berço (34\%), a Acreditar (16\%) e a campanha da União Zoófila (14\%). Contudo é de sublinhar que cerca de $18 \%$ dos inquiridos referiu não se lembrar de nenhuma campanha, o que acaba por ser sintomático da falta de envolvimento emocional neste tipo de iniciativas (ver Gráfico 5).

Gráfico 5 - Campanhas recordadas pelos inquiridos (pergunta de resposta espontânea)

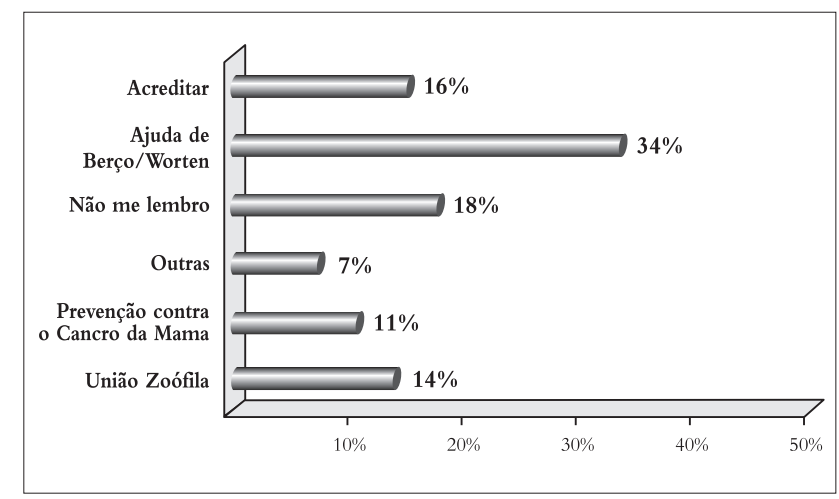

\section{Discussão dos resultados}

De acordo com os inquiridos, as redes sociais são o local indicado para a difusão de campanhas, uma vez que são um meio rápido, eficaz e abrangente em termos de audiência. No entanto, as opiniões dividem-se, pois há quem acredite que ajudar não é apenas carregar num botão, ou seja, é necessário uma maior participação, e o activismo não pode ser apenas um "activismo like". No entanto, e algo a considerar, é a pressão social que estas redes impõem entre pares: ao passarmos a mensagem, esperamos que os nossos amigos também o façam e estes, muitas vezes, sentem-se constrangidos e fazem-no para não serem "malvistos". As redes sociais são, por isso, actualmente, um dos meios mais eficazes para as campanhas de causas sociais, especialmente as que pretendam atingir o público que se encontra nestas redes (jovem, com formação académica, com poder económico) e que não exijam esforço físico nem "perda de tempo".

Uma das questões a contemplar é, no entanto, a forma como as correntes solidárias são criadas. Algumas partem da intenção das instituições e outras são uma parceria entre elas e diversas empresas, sendo o processo sempre o mesmo: adicionar a página da marca no Facebook e, quando o limite de amigos é atingido, passar a carregar no botão like. Ambas as atitudes darão origem a uma doação monetária por parte da empresa. Segundo os resultados do inquérito, cerca de $44 \%$ dos inquiridos participaram nestas campanhas através dos mecanismos acima referidos. Resta, por isso, ponderar se esta mobilização através da internet é efectivamente uma participação activa ou um exemplo de slacktivismo. Para conseguirmos perceber, é necessário avaliar os resultados das campanhas.

As campanhas solidárias do Facebook destacamse pela mobilização que implicam e pela forma concreta de ajudar: por cada amigo ou like, na página da marca, esta doaria alguns cêntimos à instituição. A campanha Acreditar, que consistia em clicar no botão like em troca de 20 cêntimos doados pela Westrangs à instituição de caridade Acreditar obteve um resultado de $€ 2.350$. Isto significa que a empresa recebeu 11.750 visitas na sua página, autopromovendo-se a custos baixos. Na campanha da Liga Portuguesa Contra o Cancro, que consistia em acumular fãs a troco de $1 €$ doado pela Roche Farmacêutica, o valor de retorno alcançado foi de 80.000 fãs e uma doação de $80.000 €$.

Os valores conseguidos foram expressivos, o que torna a participação válida, dado que produziu resultados visíveis. Quanto às campanhas mais conhecidas, o fato de a campanha da Worten ser a mais reconhecida não é de todo uma novidade, uma vez que esta era anunciada na televisão.

Por outro lado, é preciso ter em conta o objectivo das campanhas: angariar donativos, conseguir amigos no Facebook, levar as pessoas a visitar as instituições? Se a finalidade destas campanhas é conseguir donativos, então o objectivo foi alcançado. No entanto, o problema é que esta participação não é continuada, um dos grandes problemas desta forma de participar, uma vez que estando as páginas adicionadas ao Facebook, os utilizadores seguem em frente... e sempre com as informações no seu mural, da empresa que adicionaram para auxiliar uma instituição. É o "preço" a pagar por este tipo de ajuda em tudo semelhante 
à moeda que se dá ao mendigo na rua. Que acaba por lançar a dúvida sobre se estaremos perante objectivos solidários, de "responsabilidade social" ou perante objectivos comerciais. Afinal, mais do que uma contribuição para as causas apoiadas, estas campanhas resultam no aumento da notoriedade das marcas que as promovem. E quanto "mais fácil, rápido e abrangente" for apoiar a causa, maior a probabilidade de os internautas participarem (como visto pelos resultados do inquérito).

\section{Conclusões}

A realização deste trabalho elucida-nos sobre a relação entre as redes sociais e a participação dos utilizadores da internet em causas sociais. Estas passam agora por uma nova fase, uma vez que recorrem à internet, que, com o seu potencial, permite um acesso e maior participação nas campanhas. Como anteriormente referido, várias campanhas lançadas e divulgadas na rede social Facebook têm como intenção a promoção das marcas associadas, tornando-as conhecidas e relacionando-as com causas sociais, evidenciando a sua "responsabilidade social".

O cyberactivismo, a nova forma de intervir socialmente através da internet, tem vários parâmetros e permite que uma campanha tenha maior impacto, seja transmitida com maior rapidez e tenha um maior sucesso, dado o alcance da rede. Contudo, a atitude dos utilizadores continua a ser passiva, uma vez que o activismo like não implica envolvimento nem uma participação off-line, exigindo apenas que se pressione a opção "like".

Apesar da inércia dos utilizadores, a nova forma de participação tem um impacto positivo, pois faz circular mensagens comerciais e de sensibilização e dá origem a donativos a instituições de solidariedade social. É quase um primeiro passo, que não existia antigamente e com o qual os cibernautas parecem confortáveis, sem oferecer grandes resistências, pois não exige investimento físico, nem monetário.

Esta é por isso uma nova forma de participação nas causas e movimentos sociais. Talvez não a melhor, uma vez que, normalmente, termina após o clique. No entanto, é de reforçar a ideia que é mais uma opção que vai continuar a ganhar fãs. Caberá aos utilizadores decidirem se querem ou não continuar com o seu apoio como subscritores. Apoio passivo? Talvez. Mas não deixa de ser um apoio, tornado possível com a internet e com as redes sociais. Nas palavras de Danitz \& Strobel: "more than any other technology, it permits its users to create and sustain far-flung networks based on common interests or concerns of the members, where none existed before" (2001, p. 138).

\section{Referências}

CARPINI, Michael X.; KEETER, Scott. The Internet and an informed citizenry. In: ANDERSON, D. \& CORNFIELD, M. (Eds.), The civic Web. Lanham, MD: Rowman \& Littlefield Publishers, Inc. 2002, p. 129-152.. CHADWICK, Andrew. Web 2.0: new challenges for the study of e-democracy in an era of informational exuberance. I/S Journal of Law and Policy for the Information Society, 5(1), 2009, p. 9-42.

(Comp). Internet politics: states, citizens, and new communication technologies. London: Oxford University Press, 2006.

COLEMAN, Stephen. New media and democratic politics. New Media \& Society, 1, 1999, p. 67-74.

DAHLGREN, Peter. The public sphere and the net: structure, space, and communication. In: BENNETT, W.L. \& ENTMAN, R.M. (Eds.), Mediated Politics. Communication in the future of democracy. New York: Cambridge University Press, 2001, p. 33-55.

DANITZ, Tiffany; STROBEL, Warren P. Networking dissent: cyber activists use The internet to promote democracy in Burma. In: ARQUILLA, John; RONFELDT, David (Eds). Networks and netwars: the future of terror, crime, and militancy. Santa Monica, CA: Rand Corporation, 2001, p. 129-169.

DENNING, Dorothy E. Activism, Hacktivism, and cyberterrorism: The internet as a tool for influencing foreign policy. In: (Comp.). Networks and netwars: the future of terror, crime, and militancy. Santa Monica, CA: Rand Corporation, 2001, p. 239-288.

FERBER, Paul; FOLTZ, Franz; PUGLIESE, Rudy. Cyberdemocracy and on-line politics: a new model of interactivity. Bulletin of Science, Technology and Society, 27(5), 2007, p. 391-400.

HAGUE, Barry. N.; LOADER, Brian D. (Eds.). Digital democracy. Discourse and decision making in the information age. London: Routledge, 1999.

HART, Kim, GREENWELL, Megan, to Nonprofits Seeking Cash, Facebook App isn't So Green, 2009. Disponível em: http://www.washingtonpost.com/wp-dyn/content/ article/2009/04/21/AR2009042103786.html. Acesso em: 3 nov. 2010.

HERRNSON, Paul S., STOKES-BROWN, Atiya Kai; HINDMAN, Matthew. Campaign politics and the digital divide: constituency characteristics, strategic considerations. 
Political Research Quarterly, 60, p. 31-42, 2007.

HOWARD, Philip N. Deep Democracy, Thin citizenship: the impact of digital media in political campaign strategy. The Annals of the American Academy of Political and Social Science, 597, 2005, p. 153-170.

; JONES, Steve. Society on-line: the Internet in context. London: Sage Publications, 2004.

JENKINS, Henry et al. Confronting the challenges of participatory culture. Media education for the 21st century. Cambridge, MA: MIT Press, 2009.

KATZ, Jan. The digital citizen. Wired Magazine, 1997. Acesso em: 12 dez. 2009, from: http://www.wired.com/ wired/archive/5.12/netizen_pr.htm.

LANGMAN, Laura; MORRIS, Douglas. Internet mediation: a theory of alternative globalization movements. Department of Sociology, Loyola University of Chicago, USA. 2003. Disponível em: http://is.njit.edu/vci/iwci1/ morris-Internet-mediation.doc. Acesso em: 18 dez. 2010. LIVINGSTON, Geoff, Social networks and social causes, 2009. Disponível em: http://mashable.com/2009/03/26/ social-media-nonprofit-study/. Acesso em: 3 nov. 2010 MARIA, Eleonora di; RIZZO, Luca S. E-Democracy: the participation of citizens and new forms of the decisionmaking process. In: MARIA, E.; MICELLI, S. (Eds.), On line citizenship. Emerging technologies for European cities. Boston: Springer, 2005, p. 71-106.

MCQUAIL, Dennis. Mass communication theory. 4. ed. London: Sage Publications, 2000.

MIRANDILLA, Mary G. Cybercampaigning for 2010: the use and effectiveness of websites and social networking sites as campaign platforms for the 2010 Philippine presidential election. $8 \mathrm{dez}$. 2009. Social Science Research Network: http://papers.ssrn.com/sol3/papers.cfm?abstract_ id=1553724. Acesso em: 25 fev. 2011.

MOREIRA, Carlos, Diogo. Teorias e práticas de investigação. Lisboa: ISCSP, 2007

MOROZOV, Evgeny, The brave new world of slacktivism, 2009, Disponível em: http://neteffect.foreignpolicy.com/ posts/2009/05/19/the_brave_new_world_of_slacktivism. Acesso em: 21 dez. 2010.

MOSSBERGER, Karen; TOLBERT, Caroline J.; MCNEAL, Ramona S. Digital citizenship: the internet, society, and participation. London: MIT Press, 2008.

NORRIS, Pippa. Digital Divide. Civic engagement, information poverty, and the internet worldwide. Cambridge: Cambridge University Press, 2001.

OATES, Sarah; GIBSON, Rachel K. The Internet, civil society and democracy. In:n OATES, S.; OWEN, D; GIBSON, R. (Eds.). The Internet and politics. citizens, voters and activists. London: Routledge, p. 1-16, 2006.

PARK, H. M., \& PERRY, J. L. Do campaign web sites really matter in electoral civic engagement? Empirical evidence from the 2004 post-election internet tracking survey. Social Science Computer Review, 26(2), 2008, p. 190-212.

PASSY, Florence. Social Networks Matter. But How?, Social Movements Analysis: The Network Perspective, Oxford University Press. 2002. Disponível em: http://www. ssc.wisc.edu/ oliver/PROTESTS/NetworkPapers/ Passy\%20Mar011.pdf. Acesso em: 25 set. 2011

; GIUGNI, Marco. Social networks and individual preferences: explaining differential participation in social movements. Department of political science, American Sociological Association Section on Collective Behavior and Social Movements Working Paper Series, v. 2, $\mathrm{n}^{\circ}$ 2. 1998. Disponível em: http://www.nd.edu/ dmyers/ cbsm/vol2/passy.pdf, Acesso em: 22 dez. 2010.

RASH, Wayne. Politics on the Net: wiring the political process. New York: W. H. Freeman, 1997.

RHEINGOLD, Howard. The virtual community: finding connections in a computerised world. London: Minerva, 1995.

RICHARDS, Kelli, Social networking and social causes, 2007. Disponível em: http://blogs.oreilly.com/ digitalmedia/2007/08/social-networking-and-social-c-1. html. Acesso em: 22 dez. 2010.

SCHERER-WARREN, Ilse. Das mobilizações às redes de movimentos sociais, 2006. Disponível em: http://www. scielo.br/pdf/se/v21n1/v21n1a07.pdf). Acesso em: 2 nov. 2010.

SHANE, Peter M. (Ed.). Democracy on-line. The prospects for political renewal through the internet. New York: Routledge, 2004.

TOFFLER, Alvin; TOFFLER, Heidi. Creating a new civilization: the politics of the third wave. Atlanta: Turner Publications, 1995.

WILHELM, Anthony G. Democracy in the digital age: challenges to political life in cyberspace. New York: Routledge, 2000.

WITSCHGE, Tamara. On-line deliberation: possibilities of the internet for deliberative democracy. In: SHANE, P.M. (Ed.), Democracy on-line. The prospects for political renewal through the internet. New York: Routledge, 2004, p. 109-122. 


\title{
Like activism: social networks and mobilization for causes
}

\author{
Abstract \\ This article examines how the internet and the social causes are related in a political participation and cyberactivism context. To \\ understand users' reaction and the type of participation in such campaigns, a Facebook social cause campaigns analysis was made and \\ social network users answered an on-line survey.
}

Key words: internet, social networks, Facebook, social causes, campaigns.

\section{El activismo like: redes sociales y la movilización de las causas}

\section{Resumen}

Este artículo examina cómo las causas sociales la Internet se relacionan en un contexto de participación política y de ciberactivismo. Hemos hecho un análisis de las campañas para causas sociales en Facebook y una encuesta en línea a usuarios de la web y de las redes sociales, con el fin de comprender su reacción y el tipo de participación en estas campañas.

Palabras-clave: internet, redes sociales, Facebook, causas sociales, campañas.

Data de recebimento do artigo: 10/11/2011

Data de aprovação do artigo: 29/01/2012

\section{$\underline{\text { Anexo }}$ \\ Inquérito}

\section{Causas Sociais e Redes Sociais}

Este questionário pretende investigar a relação das redes sociais com os movimentos de causas sociais. O questionário é totalmente anónimo, tendo os seguintes objectivos:

1. saber se os utilizadores participam em causas sociais nas redes sociais;

2. investigar como participam nas mesmas;

3. identificar algumas das campanhas mais reconhecidas pelos utilizadores de redes sociais

Obrigado pela sua colaboração.

Parte superior do formulário

1. Tem algum perfil em redes sociais? Se sim, qual ou quais? (Se não tem, passe para a pergunta 4)

2. Já se associou a alguma causa nessa(s) redes? Se Sim, qual ou quais?

2.1. Por quê. Mesmo que nunca tenha participado justifique por que e passe para a pergunta 3

2.2. Participou? De que forma?

3. Considera que as redes sociais são um bom local para a difusão de causas sociais? Por quê?

4. 4.Qual a última campanha que se lembra de ter visto numa rede social?

5. Sexo

a. F

b. $\mathrm{M}$

6. Idade

7. Distrito de residência

8. Ocupação principal 